Joe Slater*

\title{
Miller's Tale: Why the Sympathy Principle is Inadequate
}

https://doi.org/10.1515/krt-2021-0006

Published online March 16, 2021

Abstract: In the aftermath of Peter Singer's 'Famine, Affluence and Morality', the argument he put forward received significant criticism, largely on the grounds that it demanded too much of moral agents. Several attempts have been made since to formulate moral principles that adequately express the stringency of our duties of beneficence. Richard Miller proposed one such option, which has several advantages over Singer's principle. In particular, because it concerns our dispositions rather than operating over every possible occasion for beneficence, it avoids problems of iterative demands. However, I argue that Miller's principle is inadequate, because 1) it seems too weak, 2) it appears to be ambiguous and 3) it can give unduly harsh verdicts on unlucky moral agents.

Keywords: beneficence, moral obligation, Peter Singer, Richard Miller, global poverty

In 'Famine, Affluence and Morality', Peter Singer endorses the moral principle that "If it is in our power to prevent something very bad from happening, without thereby sacrificing anything of comparable moral importance, we ought, morally, to do it" (henceforth Sacrifice) (Singer 1972, p. 231). Starting with this plausiblesounding principle, Singer argues that our obligations are extensive, that what most of us consider to be optional acts of charity are in fact our duties.

Significant attention has been paid to Singer's argument. Many are critical of the extreme demands that his principle implies. As Julia Driver notes, Singer's principle would not only require us to rescue nearby drowning toddlers from ponds, but also suggests we must "forgo buying beanie babies, new stereos, and so on in order to send money to Oxfam to be used to save lives" (Driver 2007, pp. 6869). The principle entails that when we buy luxury goods, of minimal moral significance, rather than contribute to the life-saving efforts, we do wrong. Even someone donating $30 \%$ of their income and volunteering twice a week would be deemed as morally failing, because they prevent more bad events without

*Corresponding author: Joe Slater, Department of Philosophy, University of St Andrews, Edgecliffe, The Scores, St Andrews, Fife KY16 9AL, UK, E-mail: js558@st-andrews.ac.uk 
sacrificing anything of comparable moral significance. ${ }^{1}$ Most of us would view such a person as morally admirable, which seems to be in tension with this verdict that they are doing something wrong. This leads to the common complaint that this principle is excessively demanding.

There are a variety of responses to this criticism. Some have gone to pains to show that while it may be highly counterintuitive, Singer's conclusion is actually correct. ${ }^{2}$ Others have rejected the principle, and favoured verdicts concerning our duties of beneficence that fall out of alternative moral theories. ${ }^{3}$ Another type of response holds that Singer's view is too demanding, but that the project of finding a suitable principle that governs our duties is a fruitful one.

One noteworthy attempt of this sort came courtesy of Liam Murphy, whose 'Collective Principle of Beneficence' states that "a person need never sacrifice so much that he would end up less well-off than he would be under full compliance from now on, but within that constraint he must do as much good as possible" (Murphy 2000, p. 117). ${ }^{4}$ This attempt has received some critical attention, and dealt (I think) a fatal blow by Garrett Cullity, who showed that the principle gives oddly permissive verdicts when the size of a group of would-be helpers changes. ${ }^{5}$

A recent proposal for a candidate principle comes from the Effective Altruists, William MacAskill, Andreas Mogensen and Toby Ord suggest a very weak principle of sacrifice, which states only that Most middle-class members of affluent countries, ought, morally, to use at least $10 \%$ of their income to effectively improve the lives of others (MacAskill, Mogensen, and Ord 2018, p. 179). This has already received some critical attention and has been noted to be ambiguous and susceptible to rationalising (Slater 2020, p. 466).

In this paper, I consider another candidate principle, developed by Richard Miller. ${ }^{6}$ The Principle of Sympathy is an attractive candidate, as it does give us

1 Brian McElwee gives this example as a problem for maximising forms of consequentialism, but Singer's principle - despite not being a maximising principle - also delivers this verdict (McElwee 2010, p. 395).

2 E.g. Peter Unger's Living High and Letting Die (Unger 1996).

3 E.g. Brad Hooker sees the more moderate demands of his rule-consequentialism as a major selling point (Hooker 2009), Thomas Hill thinks a Kantian perspective gives a more convincing account (Hill 2018) and Christine Swanton argues that proper consideration of the virtues gives us more satisfactory answers (Swanton 2009, 2018). Similarly, Samuel Scheffler suggests that we have special agent-centred prerogatives, permissions to give ourselves extra weighting when making these decisions, and applying these can give us more palatable verdicts when considering our duties of beneficence (Scheffler 1982).

4 This is the shortened version. The longer version, which Murphy admits is 'terribly complex'. 5 Cullity's objection is discussed extensively in The Moral Demands of Affluence (Cullity 2004).

6 Miller introduces the principle in 'Beneficence, Duty and Distance' (Miller 2004) and discusses it further in Globalizing Justice: The Ethics of Poverty and Power (Miller 2010). 
many of the kinds of verdicts we would like, i.e. that wealthy people ought to give non-negligible sums of their incomes to the world's poor (more than most in fact do), but looks able to avoid the extreme kinds of demands that Singer's principle gives us.

In Section 1, I present the important features of Miller's principle, and the discuss the verdicts he intends it to give us. In Section 2, I argue that in some cases, it looks too weak, letting some wealthy people 'off the hook'. Third, I argue that the principle is ambiguous between three interpretations, each with carry significant problems. Finally, I argue that in the interpretation most likely to have been intended by Miller, the principle is unfairly harsh on poorer agents who become surprisingly successful. Due to these criticisms, I argue that Miller's principle should be rejected as inadequate. Finally, I reflect on what this means for the search for a principle of beneficence.

\section{Miller's Underlying Dispositions}

Richard Miller sees his project as a direct reaction to Peter Singer's extremism. He concedes that while Singer's principle looks extremely plausible, upon reflection, its demandingness "misconstrues ordinary morality" (Miller 2004, p. 358). In particular, he finds it implausible that it is morally impermissible for a person to indulge in occasional luxuries. Miller thinks it is desirable to find a more moderate position, which would permit "many purchases Singer would prohibit while condemning callous indifference” (Miller 2004, p. 358). Repeatedly, Miller notes that he seeks a principle which can be more aligned with ordinary morality or ordinary moral thinking (Miller 2004, p. 358 et passim.).

In opposition to Singer, Miller proposes a more moderate account of our duties of beneficence, based on the 'Principle of Sympathy' (henceforth Sympathy.) that:

One's underlying disposition to respond to neediness as such ought to be sufficiently demanding that giving which would express greater underlying concern would impose a significant risk of worsening one's life, if one fulfilled all further responsibilities; and it need not be any more demanding than this.” (Miller 2004, p. 359) ${ }^{7}$

Rather than focussing on individual acts, Miller's principle examines the appropriate attitude of concern an agent should have. This concern is an "underlying disposition", which should be demanding enough that expressing more concern

7 Miller also defends this principle in the first chapter of Globalizing Justice: The Ethics of Poverty and Power (Miller 2010). 
would risk making one's life worse. ${ }^{8}$ Miller is clear that the suggestion that minor reductions in the quality of goods in some instances or other trivial events do not count as worsening one's life. Against the possible counter-claim that such trivialities do worsen one's life, but only by an insignificant amount, he doesn't offer a rebuttal, but instead suggests that such opponents recalibrate the view to treat "significant risk of worsening one's life" as short for "significant risk of significantly worsening one's life” (Miller 2004, p. 359).

Miller makes a distinction between underlying dispositions, which express basic concerns in a coarse-grained way, from personal policies, which are "specific standing commitments" (Miller 2004, p. 360). Underlying dispositions are the subject of Sympathy. A similar disposition may, in different people provoke a different response, based on one's inclinations, means and skill set. We may consider the disposition to help those in need in a situation where a bystander has a medical emergency. The underlying disposition will prompt one to help. If the would-be helper has medical training, this help will probably be manifested by immediate medical help, whereas if not, calling for help might be the more appropriate personal policy.

The more moderate demands entailed by Sympathy depend on what counts as significantly worsening one's life. Miller wants Sympathy to be more compatible with everyday moral commitments, thus allow agents to act in accordance with various worthwhile goals the agent identifies with, "with which he could not readily detach" (Miller 2004, p. 360). For Miller, abandoning a worthwhile goal, such as developing a sophisticated appreciation of music or expanding one's culinary horizons, does significantly worsen one's life. Clearly, Sacrifice would not allow agents such indulgences, but Miller's Sympathy does encourage people to pursue "worthwhile goals". These goals are seen as basic interests; those that give "point and value to specific choices and plans" (Miller 2004, p. 361). Miller's "basic interests" must not be confused with the interests an agent needs to merely survive, but are those interests that a person may see as essential to who they are.

Miller even defends some extravagant interests, even when their pursuit comes at the cost of donating more to the needy. Though it would allow us to relieve suffering further if we had more modest interests, once one has certain interests and one's life would be worsened if they cannot be pursued, one should

8 This may seem reminiscent of Kant's imperfect duty to beneficence. Kant holds that "beneficence is the maxim of making others' happiness one's end, and the duty to it consists in the subject's being constrained by his reason to adopt this maxim as universal law" (The Doctrine of Virtue, in The Metaphysics of Morals: §9). Imperfect duties, such as this, involve latitude, so may be discharged in various ways. Though there is some disagreement among Kantians (see Timmermann 2013; van Ackeren and Sticker 2018), several argue that for Kant, one is not morally required to help in every situation (e.g. Baron 2016; Gregor 1963; Hill 2002; Pinheiro Walla 2015). 
not be obligated to damage one's life by abandoning them. This allows Sympathy to be compatible with the occasional (and depending on the nature of the interest, even the not-so-occasional) purchase of luxury goods.

Despite this relaxing of obligations, Miller insists that Sympathy would require significantly more philanthropic activity from most of the world's non-poor, though he does acknowledge that some people with expensive tastes (e.g. if one has an "exorbitantly expensive goal that most of us lack or could readily do without") will need to "retain much more than he otherwise would to avoid worsening" their lives (Miller 2004, p. 363).

Miller offers some explanation for why he thinks particular principle is appropriate. He sees equal respect as the foundation for judgements of moral wrongness: "a choice is morally wrong if and only if it could not be made under the circumstances by someone displaying equal respect for all persons" (Miller 2004, p. 366). If equal respect for all is a good foundation from which moral claims can be deduced, and Sympathy is consistent with equal respect for all - that is, it does not provide contradictory verdicts - then Sympathy must be a good moral principle (at least with regards to what is morally wrong).

One might wonder how it is possible to respect everyone equally, yet allow some in the third world to starve, and privilege others, like oneself or one's family. To alleviate this concern, Miller notes the distinction between equal respect and equal concern. Equal concern would require that one be equally distraught by a stranger contracting a deadly illness as her child catching the same illness (which strikes most of us as undesirable). Though we may respect everyone equally, the interests of those closest to us will bring us to act more readily and more acutely than those of a stranger. Similarly, we will (generally) be more readily moved by our own needs than by those of others: Respect for others need not require us to "be prepared to do violence to who one is" (Miller 2004, p. 362). As we identify with our worthwhile goals - we see our goals as part of who we are - and we should also respect ourselves, we cannot be required to abandon these worthwhile goals. So, Miller argues, equal respect for all is consistent with Sympathy.

Miller holds that equal respect is universally acknowledged as good, and explains that it does not entail equal concern or equal treatment, but it isn't exactly clear what this lofty notion - 'equal respect' - actually means. It seems that Miller sees this as suggesting to us all a particular way of thinking about agents and requiring a degree of consideration. The term itself, “equal respect”, appears compatible with not respecting anyone at all, as long as everyone is not respected equally.

It might be that equal respect is a confused notion, but I will suppose it must involve certain features. Primarily, it must involve some appreciation that there is no agent-neutral reason to favour the interests of one person over another. It would 
be inconsistent with equal respect to promote government policies embodying a valuing of a certain culture, person or group as more valuable than another. When one manifests unequal concern, this must be because of some special relationship, and not because of a supposed difference in intrinsic value. Equal respect must also entail an acknowledgement that all moral agents have interests of their own, and a recognition that their goals have value for them in the same way our goals have value to us. I will assume for the remainder of this paper that "equal respect" is able to perform the justificatory function he supposes, though I do acknowledge that further probing could be undertaken in this avenue. Equal respect for all, we may suggest, is a common-sense moral principle that we all do and should support.

There are several problems with Sympathy, some perhaps providing only minor difficulties that could be reconciled. I argue here that some of these problems require us to deny Sympathy. Though Sympathy is supposed to provide us with a good moral principle to live by, it seems too generous to some (and possibly not to people we deem morally good), too harsh on others and, after some considerations, unclear. Next, I take these objections in turn.

\section{Sympathy Seems Too Weak}

Because of Miller's stance on “basic interests”, Sympathy may make very minimal (or no) demands of certain agents. A basic interest gives "point and value to specific choices and plans" and there is no restriction on how costly or affordable these may be (Miller 2004, p. 361). The basic interests, and the goals an individual has as a result, could be quite ostentatious. If one of my goals involves expensive travel, my life will be made worse by my inability to do so, so I could choose to take very expensive trips around the world, rather than giving to the poor. We might imagine that this expensive travel is of such a high level that no disposable income remains.

It might be suggested that this example is uncharitable. Maybe this sort of ostentatious travel or other extremely expensive activities should be excluded as possibilities for worthwhile goals that contribute to one's basic interests. Miller clearly envisages Sympathy as usually justifying only "occasionally purchasing ... luxuries and frills" (Miller 2004, p. 361), so it might be supposed that some limitation on what could suffice would be beneficial. For several people with such hobbies, Miller would claim that while such activities are enjoyed, their loss would not constitute an actual worsening of one's life. It is important not to over-rate "what merely frustrates, blowing it up into something that worsens one's life" (Miller 2004, p. 362). Several people may profess that because of their deep love of 
extravagant travel, its sacrifice would harm their lives substantially, but in doing so may merely be overstating or overestimating its importance to them.

Though some people, after reflection, may concede that they had overrated the value of ostentatious goods to their lives, it seems that some certainly would not. Some people really will identify with exorbitant habits, and see their lives as thwarted if they needed to abandon them. We might imagine someone who has the goal of visiting every capital city in the world, and exploring there, as a means to enrich herself. If she was to contemplate missing out on her extended expensive trip around South East Asia, she might feel a great sense of loss. So, rather than donating tens of thousands of dollars to an effective charity and potentially treating over 5000 people for neglected tropical illnesses for a year, ${ }^{9}$ Sympathy seems to allow her to indulge in her expensive trip.

There seems a difficulty here, as those who have had the means to develop extremely expensive habits throughout their lives must be those who have had the greatest means available. Because these people have so much, these are the types of people who we really want to give most to the world's needy. However, under Sympathy, as understood thus far, these are also the people who will be permitted to spend the most on ostentatious goods. It seems like Sympathy could be supplemented by additional premises governing which goals are worthwhile, on the basis of just how costly they are. Surely, those who spend millions on expensive art collections - when there are vast communities suffering acutely who could be relieved of their suffering with that money - are acting in an unjustifiable way? Even if we acknowledge that their donating would risk making their life worse, given the importance of what is at stake, they ought to do that.

However, Miller does argue quite explicitly against this when considering characters like Ronald Dworkin's 'Louis'. What Louis cares about is dominated by "an extremely expensive, worthwhile goal of ultra-refined savouring of food and drink meriting such sensory discrimination" (Miller 2004, p. 363). As his goal is worthwhile, the demands of Sympathy will be minimal, or none. Despite many of his neighbours living moderately austerely, Louis can revel in his expensive tastes. Nobody is required to aid Louis in his pursuit of these goals, ${ }^{10}$ as that certainly

9 E.g. to a charity such as the SCI Foundation (www.schistosomiasiscontrol initiative.org/about/ how-money-is-spent), which can treat three people for schistosomiasis for $€ 1$ (approximately $\$ 1$. 30).

10 Miller stipulates that nobody has this obligation because the "neediness" involved in Sympathy is seen as on a par with "the sort of deprivation that Singer labels "very bad"”, i.e. those needing relief from starvation or disease (Miller 2004, p. 359). Louis clearly does not fit into this category. Exactly why it is only the Singer variety of neediness that Sympathy should apply to is unstated, and perhaps warrants its own discussion, but that may prove tangential to current purposes. 
would not be required by our responsiveness to the neediness of others, but he must be allowed to use all the resources at his disposal to fulfil his goals.

Perhaps, though we may judge this as unfair, Miller would simply concede that such people would not be obligated to give as most people are. Sacrificing these particular life goals could be seen as doing damage to who Louis is as a person, and if he was to give to the needy it would be at the cost of his own identity.

This type of response, however, does seem untenable. We may imagine our other Louis-type character, who has the worthwhile goal of travelling the world. She does so in such a way that commits her to giving less to the poor than someone raised in less wealthy conditions (and who, as a consequence, has less extravagant goals). We can, by stipulation, increase the wealth of the agent and the costs required by her project, such that she is spending millions, in which case it definitely seems like she is worthy of criticism/scrutiny. In these cases, the principle seems too weak. As Elizabeth Pybus notes, "selfishness doesn't relieve us of the moral requirement to be willing to do things for other people" (Pybus 1982, p. 198). Engaging in ostentatious projects, even ones that are "worthwhile", does seem selfish and unable to justify failing to ever act beneficently. Miller sees it as an advantage of his view that it will never require agents to be "prepared to do violence to who one is" (Miller 2004, p. 362). But sometimes morality can require that, or at least I contend so.

To really emphasise this point, consider the case of Leona Helmsley. ${ }^{11}$ Helmsley was a billionaire, who was famously mean. It seems plausible that she took pride in her mean, cruel-minded persona. Cultivating this image of herself as a villainous plutocrat could even have been something that made her life better, as something she readily identified with and reflected upon with glee. Suppose that this was indeed the case. If she had adopted a disposition that made herself more responsive to the needy, she could not have nurtured this hostile reputation. Thus, by Miller's account, beneficence could not have demanded that she adopt a sympathetic disposition. Ordinary moral thinking condemns Helmsley as a cruel, selfish character. If our principle of beneficence cannot even denounce this selfish behaviour, it seems unfit for purpose.

One strategy Miller could take is to impose some restrictions on what could count as a worthwhile goal. Perhaps, we could impose a restriction against vicious goals as contributing to how well one's life goes. Miller cautioned against

11 Some features of this case may be exaggerated from the real life example - which Jeff McMahan also uses as an illustration of someone failing in their duties (MacAskill, Mogensen, and Ord 2018, p. 78), in large part because she intended that her fortune be used to benefit dogs, rather than humans - but I take it that any misrepresentations are still plausible, and thus will serve my purpose. 
“puritanical conceptions" of worthwhile goals (Miller 2004, p. 361), which would exclude any luxuries. So he would need some intermediate conception, not too restrictive, but not too liberal. Yet it is hard to see how any way of formulating this could be acceptable, because what goals it is permissible to pursue seem to depend on what is a stake. In some cases, cultivating a rude and stand-offish persona might be permissible, even at the cost of doing something nice for someone. But, as I suggest was the case in Helmsley's case, this often constitutes a moral failing. In addition, in order to a restriction like this would require a substantial - and contentious - view of what makes one's life go well, such that only morally appropriate ends count. This seems like such a departure from ordinary moral thinking that Miller would not be amenable to such a change.

Miller is committed to his principle delivering verdicts more aligned with conventional morality. This is the entire rationale for his principle. So if the principle gives verdicts that appear wildly implausible, this is, on Miller's own terms, grounds for rejection. This at least seems problematic for Miller's account, if not a knock-down objection.

\section{Sympathy is Not a Clear Principle}

Though Miller may simply bite the bullet in the types of cases described above, the following problem demands a response. Sympathy holds that our underlying dispositions to respond to neediness should not be more demanding than would "impose a significant risk of worsening one's life". Miller does not elaborate what he considers a significant "worsening" of one's life to be. Crucial to making any sense of this principle, is some idea of what the baseline for comparison is.

For a "worsening" to occur, there must be a relation between two situations, one judged as better and the other worse. To undergo a "worsening" because of a certain choice, the agent must then be seen as selecting the worse of two options. I propose three interpretations for how this may be understood:

a) A worsening of one's foreseen expected future,

b) A worsening in comparison to everyone else, and

c) A worsening compared to one's situation before one gives.

\section{1 (a) Worsening of a Foreseen Future}

This interpretation relies on some notion of an "expected life" which an agent's life could be better/worse than. This particular version seems to have most support from Miller's comments: When introducing the principle, Miller claims that the 
significant risk of worsening one's life means a "nontrivial chance that one's life as a whole will be worse than it would otherwise be" (Miller 2004, p. 359). Even this option seems slightly ambiguous. If we suppose we are considering donating a certain amount of money to charity, is the quality of our life under this level of giving supposed to be compared to the situations where we give nothing, or to our current level of giving (supposing that we are already donating some amount)?

The first of these options seems likely to be problematic when evaluated by people on middle-incomes who give a small to moderate amount already. Consider Noah, who earns a modest income - enough to survive, put some money away for a rainy day and have a little disposable income to spend on the occasional luxury and through his life has been moved by many of the disaster appeals or OXFAM adverts and gives 10\% of his income. He also has a passion for nice whisky. Upon thinking about Sympathy, he concludes (rightly) that his enjoyment of whisky is a worthwhile goal. He also calculates that if he ceased to give at his current level, he would be able to buy an additional nice bottle of whisky every month, with the hope of expanding his pallet.

Most people will seem to have an interest or passion similar to Noah's, one that they will identify with and that will enrich their lives if properly pursued. It might also be the case (and I suspect it is) ${ }^{12}$ that the vast majority of these could pursue such goals much more successfully (to the extent that lacking this would make them substantially worse off). If correct, this would lead not, as Miller claims, to people giving much more of their incomes to the needy, but potentially much less.

The second suggestion for this interpretation might result in situations more similar to those Miller envisages. Noah, and the vast middle-classes, would judge whether giving an additional amount to their current donations would lead to the pursuit of their goals being substantially less successful and consequently worsen their lives. However, basing what should be given merely on one's current giving practises seems somewhat arbitrary, and Miller claims that this is something he aims to avoid (Miller 2004, p. 370). This also might seem to unfairly disadvantage those who are already donating a non-negligible amount of their income, as they would not be comparing to an egoistically ideal possible future.

\section{2 (b) Worsening of a Future in Comparison to Others}

One possible interpretation that might be taken could set the ordinary, status quo of giving as the grounds for comparison. This interpretation seems the least

12 This is an empirical matter, and also subject to rationalising, which may add difficulties to the application of Sympathy. 
plausible, but still worthy of mention. It might be thought that all affluent people should be donating, and furthermore that everyone in a similar position should be donating a similar amount. If a small amount of people donate substantial amounts of their earnings, while others earning similar amounts in their community give little or nothing, those who do donate may find themselves in relative poverty. We might see that as objectionable, so conclude that one's donations shouldn't leave them worse off within their own local society.

This interpretation seems to allow for a "collusion" of not giving, so that no one worsens their lives compared to everyone else in their position. As Miller's principle is also couched very cautiously - even risking worsening one's life is motivation enough to warrant not giving additional money - it might even lead to people reducing their donations, because otherwise they may risk worsening their position in society.

\section{3 (c) Worsening in Comparison to Pre-Giving State}

One natural interpretation of the "worsening" Miller refers to is in comparison to one's state before they make their donation. As I have already mentioned, Miller does suggest that the comparison should be against what an agent's situation would be otherwise, not before. However, this interpretation should be mentioned, as it would be an alternative if it did not pose significant issues of its own (though I will suggest that it does).

Independently of any donations to charities, people will experience increases or decreases in their standards of well-being. Whether due to changes in income, the cost of living or any number of non-financial factors, an agent's well-being is unlikely to be constant. People in relative poverty may become quite affluent, and vice versa. On one extreme, we may imagine a young socialite from a very wealthy family, but who earns nothing. Despite inheriting several houses, her life is very likely to be substantially worsened if she gives money to charities, simply because her quality of life is likely to worsen anyway, certainly over a long period of time. Perhaps several of the family homes will have to be sold to pay for a very expensive lifestyle (full of worthwhile goals, we may assume for the sake of this argument) and this is certain to impact her quality of life.

This interpretation may then lead to the unsatisfactory conclusion of some of the wealthy elite having no duties of beneficence. The example could also be ran the other way. A moral agent trying to improve her station in life would be obligated to give at a level such that it wouldn't risk worsening her life from that starting position. If an agent's life is unlikely to be worsened - because of a poor starting position - no matter how hard she works, this interpretation would require 
her to remain in a similar position. As well as obviously being contrary to Miller's purpose, a principle like this would impede social mobility to an abhorrent degree. In the next section, I consider further ways that Sympathy might look too demanding, and have a similarly unjust effect on social mobility, even under the first interpretation of worsening.

\section{Sympathy Seems Too Demanding}

Given that the first objection I raised to Sympathy was that it was too weak, it might seem peculiar to claim that it is also too demanding. However, just as the principle seemed too weak with regards to a certain group of society (namely, rich people with ostentatious hobbies), it is (at least sometimes) too harsh on less wealthy people.

As mentioned previously, it seems clear that Miller did intend Sympathy to require agents to compare how their life would be if they donated extra to a possible future that could be expected if they did not. This might also be the most plausible interpretation of the principle. However, despite the earlier objection that Sympathy might be too weak, this interpretation can actually be very demanding for certain moral agents.

I suggest this because of how we are likely to envisage expected possible futures. Consider Sally, a child from a western family who grows up in relative poverty. Sally's family is heavily reliant on benefits throughout her youth and as a result she is well-fed and educated, but not affluent. She works very hard and is rewarded by occasional promotions. Sally is humble, however, and whenever greeted by a promotion is surprised, and does not expect to receive another. She does not expect to ever earn enough to satisfactorily pursue her worthwhile goals. Because Sally does not think she can pursue these goals to a degree that would further enrich her life, she regards Sympathy as commanding that she adopt a very high level of underlying concern, as she does not believe doing so is likely to worsen her life by hindering these goals.

As Sally's tale is intended to illustrate, this interpretation of Sympathy can also result in a hindering of social mobility. We might suppose that if Sally had an accurate idea of how her circumstances would change, she would have realised that she would comfortably have been able pursue her goals. Miller could respond to this criticism by claiming that rather than what an agent actually expects, the principle concerns rational expectation, or what one should reasonably expect. This could mitigate problems caused by Sally systematically underestimating the prosperity in her future. However, to bring out the problem, we need not make use of a case with an agent who underestimates their potential to fulfil their goals as 
much as Sally does. If an agent becomes accustomed to a more austere lifestyle, they are unlikely to identify with more glamorous goals, even if they may be attainable. ${ }^{13}$ Childhood dreams of pursuing an exciting career are likely to be left unfulfilled by most. An alternative position one could take on Sympathy might suggest that even childhood dreams or fantasies do count as worthwhile goals one identifies with, but this interpretation would minimise to the point of negligibility any duties of beneficence in such cases.

\section{Rejecting Miller's View}

Though Sympathy is able to respond to several of the problems levied against Sacrifice, it carries a lot of baggage of its own. Even when the principle is properly specified, the obligations it generates seem extremely unjust. It strikes many as obvious that the bulk of our obligations to the poor should fall at the hands of the rich, as they are the most able to do something about it. Sympathy, however, seems too many of the rich 'off the hook', while having the unintended consequence of restricting the spending of the poor to the minimal luxuries they may have become accustomed to.

The switch from Singer's principle, focussing on individual actions, to a principle which concerns underlying dispositions, appeared to be promising. Because of this, it is able to satisfactorily avoid several of the problems Sacrifice faces and give appropriate responses to various problem cases. However, the objections offered here suggest that, as is often the case with principles of this sort, further scrutiny raises complications.

Furthermore, the objections raised here pose important challenges to any account of our duties of beneficence that employs implicit comparisons between ways our lives could be. Singer avoids this problem, because his principle operates over individual actions, where one's choice is (apparently) to make the sacrifice or not. As each individual moment of choice typically does not sacrifice anything of major moral significance, Singer's principle ends up being extremely demanding. Miller's move looks like it avoids this, but the move to underlying dispositions opens up a much wider range of possible lives for comparison.

Where does this leave the quest for an adequate principle of beneficence? Miller's move to a coarse-grained approach, governing a disposition or general attitude as opposed to individual acts does seem promising. A tempting option can be found viewing duties of beneficence in a similar way to Kantians, as imperfect

13 We might consider Isaiah Berlin's example of an agent who has adapted their preferences to be so minimal that their desires are all satisfied even under a tyrant (Berlin 2002, p. 182). 
duties. This need not imply that helping is always optional, and might on some occasions issue a requirement where Miller's principle would not. Adopting a maxim of beneficence requires that one make the ends of another person one's own. One must really have a commitment to the good of others. Sometimes, as Alice Pinheiro Walla points out, refusing to help "would amount to giving up one's commitment to beneficence altogether" (Pinheiro Walla 2015, p. 734). This seems to be the case in the most egregious examples I have given in this discussion.

Utilising imperfect duties leaves us with a very imprecise method for determining what beneficence requires of us. However, perhaps this is the way it should be. Perhaps, the ethics of giving are not something that can simply be derived from a general principle, but rather are a rich and complicated matter, agents must apply considered judgement in each individual case. If so, this would, reflect the general acknowledgement that Miller is correct in claiming we should manifest "equal respect", but what this means for our moral obligations is fiercely contested.

Acknowledgments: Many thanks to three anonymous referees for helpful comments which have improved this paper, and to the editors for making this process as swift and painless as possible. I would also like to thank the organisers and attendees at a MANCEPT workshop on Duties of Beneficence in 2015, where an embryonic version of this paper was given. Finally, I'd like to thank Justin Snedegar for feedback on various previous incarnations of this paper.

\section{References}

Baron, M. 2016. “A Kantian Take on the Supererogatory." Journal of Applied Philosophy 33 (4):

347-62.

Berlin, I. 2002. Liberty. Oxford: Oxford University Press.

Cullity, G. 2004. The Moral Demands of Affluence. Oxford: Clarendon Press.

Driver, J. 2007. Ethics: The Fundamentals. Oxford: Blackwell.

Gregor, M. J. 1963. Laws of Freedom: A Study of Kant's Method of Applying the Categorical Imperative in the Metapnysik der Sitten. New York: Barnes \& Noble.

Hill, T. 2002. Human Welfare and Moral Worth: Kantian Perspectives. Oxford: Oxford University Press.

Hill, T. 2018. "Duties and Choices in Philanthropic Giving: Kantian Perspectives". In The Ethics of Giving: Philosophers' Perspectives on Philanthropy, edited by P. Woodruff, 13-39. Oxford: Oxford University Press.

Hooker, B. 2009. “The Demandingness Objection”. In The Problem of Moral Demandingness, edited by T. Chappell, 148-62. Basingstoke: Palgrave MacMillan.

MacAskill, W., A. Mogensen, and T. Ord. 2018. “Giving Isn't Demanding.” In The Ethics of Giving: Philosophers' Perspectives on Philanthropy, edited by P. Woodruff, 178-203. Oxford: Oxford University Press. 
McElwee, B. 2010. "The Rights and Wrongs of Consequentialism." Philosophical Studies: An International Journal for Philosophy in the Analytic Tradition 151 (3): 393-412.

Miller, R. 2004. “Beneficence, Duty and Distance." Philosophy \& Public Affairs 32 (4): 357-83.

Miller, R. 2010. Globalizing Justice: The Ethics of Poverty and Power. Oxford: Oxford University Press.

Murphy, L. 2000. Moral Demands in Nonideal Theory. New York: Oxford University Press.

Pinheiro Walla, A. 2015. “Kant's Moral Theory and Demandingness.” Ethical Theory \& Moral Practice 18: 4.

Pybus, E. 1982. "Saints and Heroes." Philosophy 57 (220): 193-9.

Scheffler, S. 1982. The Rejection of Consequentialism. Oxford: Oxford University Press.

Singer, P. 1972. "Famine, Affluence \& Morality." Philosophy \& Public Affairs 1 (3): 229-43.

Slater, J. 2020. "Book Review: The Ethics of Giving: Philosophers' Perspectives on Philanthropy." Journal of Moral Philosophy 17 (4): 464-7.

Swanton, C. 2009. "Virtue Ethics and the Problem of Demandingness." In The Problem of Moral Demandingness, edited by T. Chappell, 104-22. Basingstoke: Palgrave MacMillan.

Swanton, C. 2018. "Virtue Ethics, Thick Concepts, and Paradoxes." In The Ethics of Giving: Philosophers' Perspectives on Philanthropy, edited by P. Woodruff, 40-77. Oxford: Oxford University Press.

Timmermann, J. 2013. “Kantian Dilemmas? Moral Conflict in Kant's Ethical Theory.” Archiv für Geschichte der Philosophie 95 (1): 36-64.

Unger, P. 1996. Living High and Letting Die: Our Illusion of Innocence. Oxford: Oxford University Press.

van Ackeren, M., and M. Sticker. 2018. "Moral Rationalism and Demandingness in Kant." Kantian Review 23 (3): 407-28. 